\title{
MACRO BENTHIC FAUNA IN RELATION TO LIMNOLOGICAL VARIABLES IN A MIGRATORY BIRD VISITING LAKE AT JAHANGIRNAGAR UNIVERSITY, BANGLADESH
}

\author{
Sharmin, S., S. H. Rahman, M. N. Naser ${ }^{1}$ and S. Hoque ${ }^{2}$ \\ Department of Environmental Sciences, Jahangirnagar University, Savar, Dhaka, Bangladesh; \\ ${ }^{1}$ Department of Zoology, University of Dhaka; ${ }^{2}$ Department of Soil, Water and Environment, University \\ of Dhaka, Dhaka, Bangladesh
}

\begin{abstract}
The abundance of macro benthic organisms was observed from a migratory bird visiting lake in Jahangirnagar University, Savar for a period from July 2016 to June 2017. A total of 22 species belonging to three phyla (viz. Mollusca, Annelida and Arthropoda) and 14 families was recorded with maximum abundance in summer season and minimum in winter season. Molluscan population $(37 \%)$ was dominant in benthos, followed by Annelida (31\%) and Arthropoda (28\%). Average values of water temperature, dissolved oxygen and water $\mathrm{pH}$ were within standard permissible ranges in the aquatic habitats of the country. Water and soil parameters were in suitable ranges for the growth and abundance of benthos. Correlation indicated that Mollusca and Annelida were closely dependent on water temperature, water $\mathrm{pH}$, water depth, soil organic carbon and soil organic matters, whereas Arthropoda had less dependency on them. In the present study lower Shanon-Wiener diversity index (2.55-2.92) and low species richness (18-24) clearly demonstrated that the lake is moderately polluted.
\end{abstract}

Key words: Macrobenthos, Mollusca, Annelida, Arthropoda, soil organic matter, diversity indices.

\section{INTRODUCTION}

Jahangirnagar University (JU) campus, known as a suitable place for migratory birds, is situated 32 $\mathrm{km}$ away from Dhaka city on the north western side. Birds are most important avian component of freshwater wetland ecosystems. Their presence or absence indicates the ecological status of a particular water body (Rajpar et al. 2010). Every year a good number of migratory birds visit and take shelter at the lakes of the Jahangirnagar University campus. The lakes are subject to water-level fluctuations, as hostel runoff and seasonal rains in the campus. Bird populations have the potentials to create eutrophication in the lakes creating a suitable environment for macrobenthos. The major food items eaten by wetland birds include small fishes, beetle, flies, grasshoppers, spider, crustaceans, earth worms, insect larvae and small mollusca (Sultana et al. 2013). The benthos under this context are different species of polychates, oligochaetes, worms, gastropods, bivalve s and various minor insect larvae. They use to inhabit in various substrates like stones, logs or leaves and even in tunnel in sediments or debris. Some are pelagic while others are free swimming in the water column for at least part of their life cycle (Rosenberg and Resh 1993). The benthic fauna take part in exchange of nutrients, dissolve gases and other materials between sediment and water through their feeding and living (burrowing) activities. George et al. (2009) reported several functions of benthic organisms, such as mixing of sediments, flux of oxygen in sediments, mineralization and cycling of organic matter. The benthic animals have an important role in aquatic food chain as most fishes, birds and other aquatic animals depend directly or indirectly on the benthos for their food supply (Barnes and Huges 1988). It also plays an important role in the decomposition and recycling of organic matters and acts as an important tool for improving water quality (Bilgrami and Munshi 1985). Various physico-chemical parameters of water and soil influence the abundance and distribution of macrobenthos. The productivity of benthos depends on water quality and water quality in turn depends on the soil properties (Nupur et al. 2013). The water quality and benthos are inter related and is used as indicator of water quality (Rosenberg and Resh 1993). Among 29 
lakes in the experimental areas only 4 lakes provide a natural aquatic habitat for winter migratory birds. The migratory bird visiting lakes are ecologically importance (Momtaz et al. 2010). It is seen that the list of birds is growing in volume incourse of the time due to availability of suitable food, diversified habitat and less anthropogenic disturbance. The present investigation was conducted to assess the variations of macro benthos in relation to limnological variations in the water and soil of the migratory bird visiting lake of the Jahangirnagar University campus.

\section{MATERIAL AND METHODS}

The experimental work was carried out in a migratory bird visiting lake in Jahangirnagar University, Savar, Bangladesh (Fig. 1). The university stands on the west side of the Asian Highway, popularly known as the Dhaka-Aricha highway. The lake covers an area of 9 acres with an annual average depth of 0.80-1.21 meter. The lake is situated in the western side of Pritilata and Jahanara Imam Halls, GPS location; Latitude- $23^{\circ} 53^{\prime} 02.3^{\prime \prime} \mathrm{N}$ and Longitude $090^{\circ} 16^{\prime} 05.9^{\prime \prime} \mathrm{E}$. The materials used in the experiments were Ekman Dredge $(15 \mathrm{~cm} \times 15 \mathrm{~cm})$, sieves of mesh size 0.2, 0.92, and $2 \mathrm{~mm}, 5 \%$ formalin, polythene bag, digital camera, permanent marker, magnifying glass, stareo microscope, digital thermometer, pocket water $\mathrm{pH}$ meter, DO meter, soil $\mathrm{pH}$ meter, concentrated sulfuric acid $\left(\mathrm{H}_{2} \mathrm{SO}_{4}\right)$, phosphoric acid $\left(\mathrm{H}_{3} \mathrm{PO}_{4}\right)$, standard IN potassium dichromate $\left(\mathrm{K}_{2} \mathrm{C}_{\mathrm{r} 2} \mathrm{O}_{7}\right)$, diphenylamine indicator solution and ferrous sulfate solution $\left(\mathrm{FeSO}_{4}\right)$. This study was carried out from July 2016 to June 2017. Samples were collected monthly in different seasons, namely monsoon (July-October), winter (November-February) and summer (March-June).
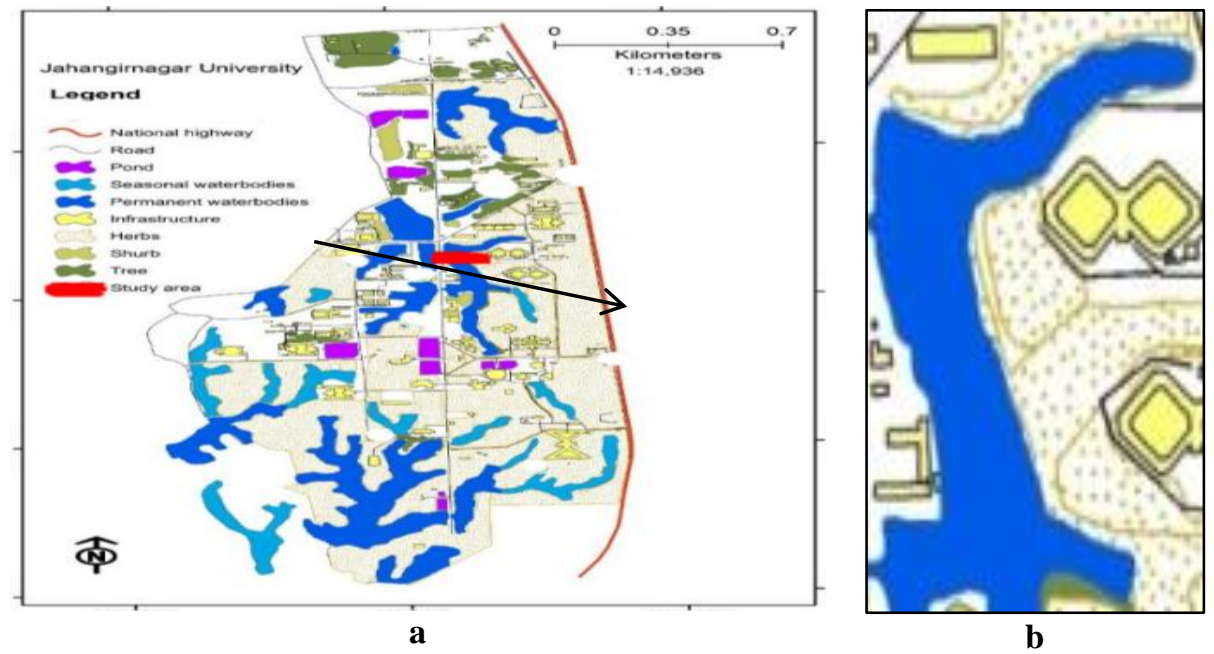

Fig.1. Map of study site: a. Jahangirnagar University indicating study area; and b. migratory bird visiting lake.

The experimental lake was divided into three sites. Two sediment samples from each site were collected by using an Ekman Dredge. After collection, the sediments were placed in a bucket and mixed with water. The mixture passed through a series of sieves of mesh size $(0.2,0.92$ and $2 \mathrm{~mm})$ in order to separate benthic organisms. Unwanted materials were removed and collected organisms were washed; and preserved in 5\% formalin then stained in rose Bengal solution (Idowu and Ugwumba 2005). Finally the samples were taken to the laboratory for further analysis. The samples were identified to the lowest possible taxonomic level by adopting methods given by Pennak (1978), Edmonson (1959), Mellanby (1971), Needham and Needham (1962), Ali and Charkraborti (1992) and Subba Rao (1992). The abundance of benthic organism was expressed as density (No. $\left./ \mathrm{m}^{2}\right)$ by the formula of Welch (1948).

During sediment sampling, water samples were collected from each site. The physico-chemical parameters of the water and soil were also measured at each sampling site both in situ and ex situ 
conditions. Air temperature, water-temperature, $\mathrm{pH}$, dissolve oxygen, water depth were measured using a digital thermometer, $\mathrm{pH}$ meter, $\mathrm{DO}$ meter. The depth of water was measured by using a rope along with a medium sized stone tied at one end of it and a meter tape in the field. The $\mathrm{pH}$ of freshly collected moist soil was determined by using Griffin pH meter (model no 40), soil organic carbon content was estimated by following wet oxidation method as described by Jackson (1973). The organic matter content of the soil was determined by multiplying the percentage of organic carbon with conventional van Bemmelen's factor of 1.724 (Piper 1950).

\section{Evaluation of diversity indices for benthos}

Diversity of benthic macro-invertebrates was statistically treated with the help of following equation: Shannon-Wiener's diversity index $\left(\mathrm{H}^{\prime}\right)$

$$
\begin{aligned}
& \mathrm{H}^{\prime}=-\sum_{\mathrm{i}=1}^{\mathrm{s}} p i \ln p i \\
& p i=\text { ni/ } \mathrm{N} \text {, where ni is the number of individuals in species } \mathrm{i} \\
& \mathrm{N}=\text { is the total number of individuals }
\end{aligned}
$$

Pielou's evenness index (J')

$$
\begin{aligned}
& \mathrm{J}^{\prime}=\mathrm{H}^{\prime} / \mathrm{H}^{\prime} \max \\
& \mathrm{H}^{\prime}=\text { the observed value of Shannon index, } \mathrm{H}^{\prime} \max =\mathrm{LN}(\mathrm{S}) \\
& \mathrm{LN}=\text { Natural Log base } \mathrm{N} \text { of the number } \\
& \mathrm{S}=\text { Total number of species }
\end{aligned}
$$

Margalef diversity index $(\mathrm{d})$

$$
\begin{aligned}
& \mathrm{d}=(\mathrm{S}-1) / \log \mathrm{N}(\mathrm{N}) \\
& \mathrm{S}=\text { Total number of species } \\
& \mathrm{N}=\text { Total number of individuals }
\end{aligned}
$$

Correlation between major group of macrobenthos and limnological parameters of water and soil was analyzed by Pearson correlation (Islam 2001). A relationship exist between species diversity and pollution status as species diversity $\mathrm{H}<1=$ low diversity, $\mathrm{H} \mathrm{1-3}=$ fair diversity and $\mathrm{H}>3=$ high diversity and $H$ value $3>=$ clean, $H$ 1-3 = moderately polluted and $H<1=$ heavily polluted. Taxa richness increase with increasing habitat diversity and water quality and value ranges 0-26 (Plafkin et al. 1989). The status of pollution in summer, monsoon and winter season was evaluated on the basis of Shannon-Wiener diversity index and taxa richness.

\begin{tabular}{|c|c|c|c|c|c|c|}
\hline \multirow{2}{*}{$\begin{array}{l}\text { Benthic } \\
\text { group }\end{array}$} & \multirow{2}{*}{$\begin{array}{c}\text { No. of } \\
\text { Species }\end{array}$} & \multicolumn{3}{|c|}{ Seasons (Ave. \pm SE) } & \multirow{2}{*}{$\begin{array}{c}\text { Total benthos } \\
\left(\mathrm{No} . / \mathbf{m}^{2}\right)\end{array}$} & \multirow{2}{*}{$\begin{array}{c}\text { Percentage } \\
(\%)\end{array}$} \\
\hline & & Monsoon & Winter & Summer & & \\
\hline Mollusca & 9 & $424 \pm 29.3$ & $373 \pm 20.6$ & $564 \pm 30.4$ & 1361 & 37 \\
\hline Annelida & 6 & $388 \pm 42.5$ & $342 \pm 15.4$ & $407 \pm 32.4$ & 1137 & 31 \\
\hline Arthropoda & 7 & $433 \pm 20.4$ & $270 \pm 28.5$ & $327 \pm 29.5$ & 1030 & 28 \\
\hline Others & - & 0 & $42 \pm 12.6$ & $82 \pm 22.2$ & 124 & 4 \\
\hline Grand total & 22 & 1245 & 1027 & 1379 & 3652 & 100 \\
\hline
\end{tabular}

\section{RESULTS AND DISCUSSION}

A total of 3652 individuals belonging to 22 species of macrobenthos from 14 families under three Phyla like Mollusca, Annelida and Arthropoda were identified. Khan et al. (2007) found 20 species belonging to 16 families in Mouri river, Khulna and Hossain et al. (2009) found 20 genera of macrobenthos in Meghna river. The results of the above authors are in close resemblance to our present findings. Qualitative and quantitative analyses show the dominance of Mollusca contributing $37 \%$ of total benthic population whereas Annelida contributing 31\%, Arthopoda 28\% and 4\% were unidentified benthos (Table 1).

Table 1. Seasonal distribution of benthic population $\left(\left(\mathrm{No} / \mathrm{m}^{2}\right)\right.$. 
Chakma et al. (2015) reported Oligochaeta and Ghosh et al. (2015) reported Arthropoda as dominant group of benthos. The present findings showed dissimilarity to the results of the above authors. Highest density of benthos was recorded in summer $38 \%$ followed by monsoon $34 \%$ and winter $28 \%$ (Fig. 2). Such summer dominance of benthos was reported earlier by Sarker et al. (2016). Phylum Mollusca dominating benthic group includes nine species under five families. Bellamya bengalensis, Lymnea accuminata, Planorbis and Gyraulus were the most dominant species of Mollusca found in all seasons whereas B. crassa, B. discimillis, L. luteola, Melanoides and Lamellidens were least abundant species with highest density in summer during the study (Fig. 3). Annelida the second dominant group of benthos had six genera belonging to four families. Tubifex spp. were most abundant and Limnodrillus, Brachiura Brachiodrillus, Lumbriculus and Hirrudinea were commonly found in all season with summer maximum (Fig. 4).

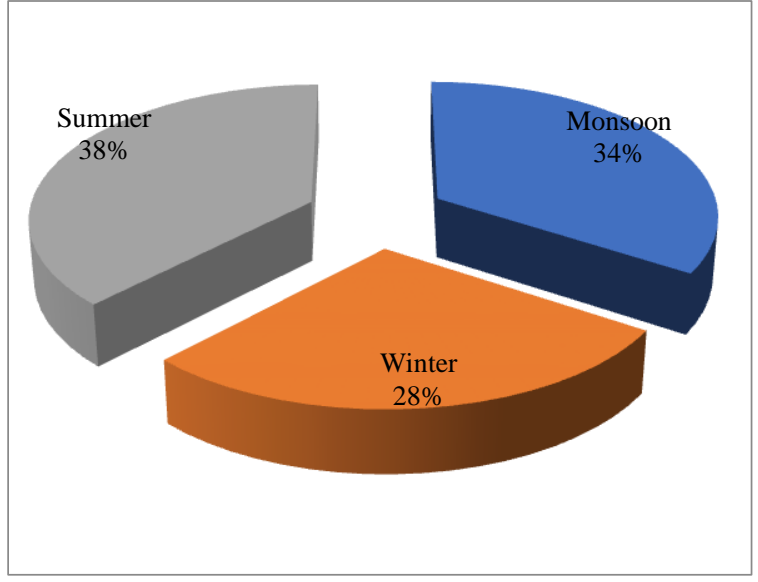

Fig. 2. Seasonal distribution of benthos in the lake.

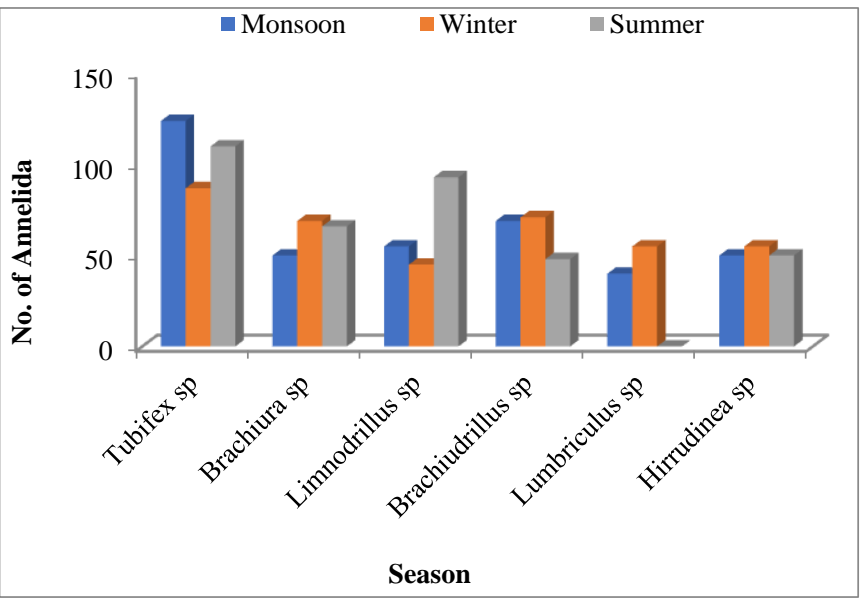

Fig. 4. Species wise seasonal distribution of Annelida in the lake.

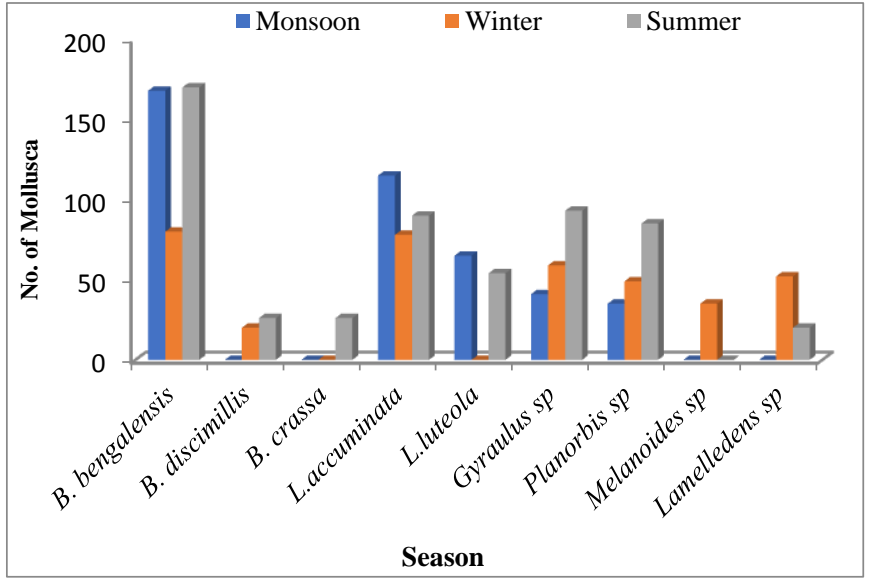

Fig. 3. Species wise seasonal distribution of Mollusca in the lake.

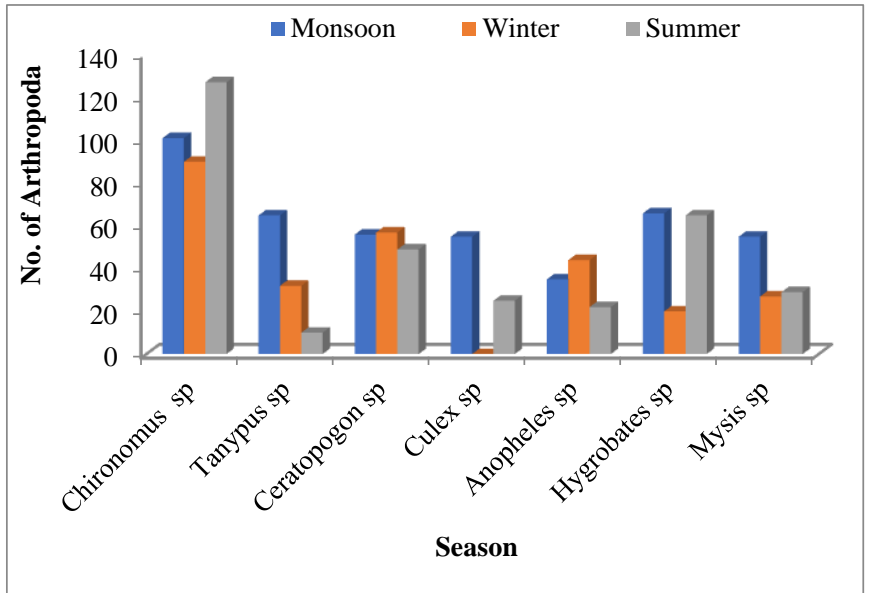

Fig. 5. Species wise seasonal distribution of Arthropoda in the lake.

Arthropoda was the third abundant group in the present study with seven species under five families. Chironomus spp. was the most abundant and Tanypus spp., Ceratopogon spp., Anopheles spp., Culex spp., Hygrobates spp. and Mysis sp. were common in all seasons but their density was highest during monsoon (Fig. 5). This type of dominance of the macro benthos was reported earlier by Nupur et al. (2013) and Khan et al. (2007). Some important photos of macrobenthos recorded during study are shown in Fig. 6. 


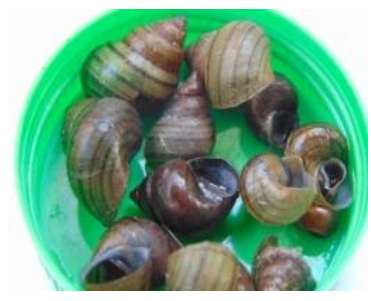

a

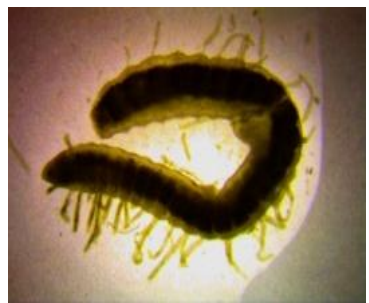

e

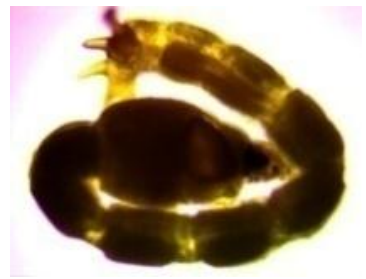

i

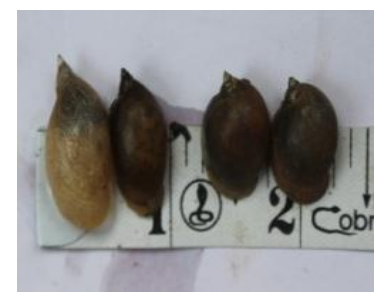

$\mathbf{b}$

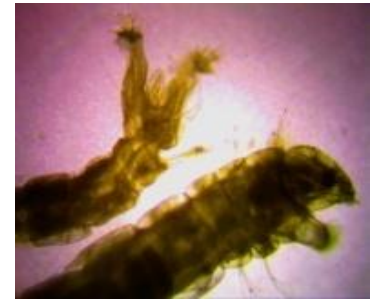

f

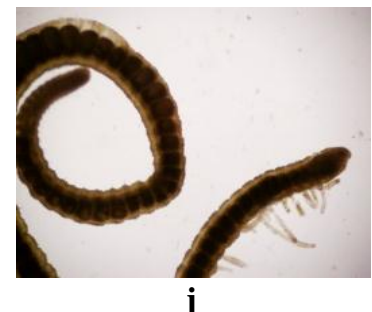

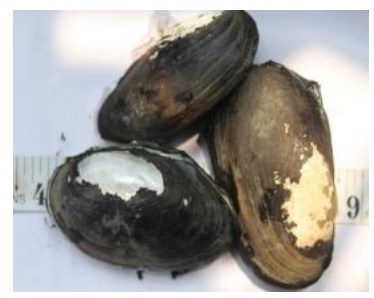

c

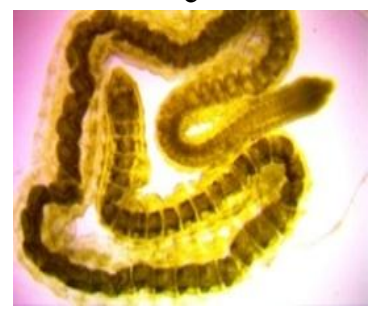

g

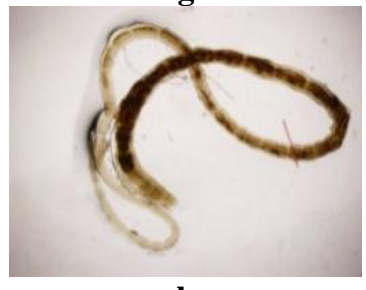

k

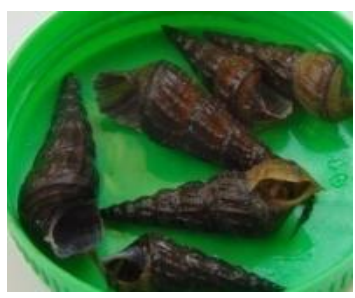

d

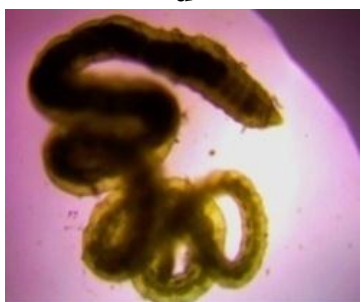

h

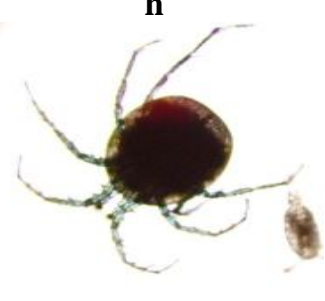

I

Fig. 6. Some examples of the dominated abundant and poorly abundant benthic species in the study area: a. Bellamya spp.; b. Lymnaea spp.; c. Lamilledens spp.; d. Melanoides spp.; e. Brachiodrillus spp.; f. Chironomus spp.; g. Tubifex spp.; h. Limnodrillus spp.; i. Tanypus spp.; j. Brachiura spp.; k. Lumbriculus spp.; and l. Hygrobatis spp.; m. Chironomus spp; and n. Tanypus spp.

Diversity indices for benthos population

Species number (S), total number of individuals (N), species diversity (Shannon-Weiner H'), species richness ( Margalef's d) and evenness (Pielou's J') recorded from the studied lake were varied in different seasons. Species diversity, species richness and species evenness recorded in different seasons were fluctuated from 2.55-2.92, 2.43-3.19 and 0.88-0.92, respectively (Table 2).

Table 2. Biological indices for benthos population.

\begin{tabular}{lccc}
\hline Diversity indices & Monsoon & Winter & Summer \\
\hline Species number (S) & 21 & 18 & 24 \\
Total individuals (N) & 1212 & 1089 & 1351 \\
species diversity (Shannon-Weiner H') & 2.85 & 2.55 & 2.92 \\
Species richness (Margalef's d) & 2.95 & 2.43 & 3.19 \\
Evenness (Pielou's J') & 0.92 & 0.88 & 0.92 \\
\hline
\end{tabular}

Species diversity, species richness and species evenness were low in winter in comparison with the other two seasons. Such diversity indices for benthos are in close agreement with Sarker et al. 2016 and such low Shanon-Wiener Value indicated the moderate pollution of the studied lake (Shannon and Wiener 1963). Besides taxa richness of present study also indicates moderate to slightly pollution of water body as stated by Plafkin et al. (1989).

\section{Physico-chemical parameters of water and soil}

The abundance of benthic fauna depends largely on the physic-chemical factors of water and soil. In the present study, the mean value of water temperature, dissolve oxygen (DO), water $\mathrm{pH}$ and water depth ranged 30.05-21.9 C, 5.93-4.06 mg/1, 7.83-6.93 and 75-120 cm, respectively (Table 3). 
Table 3. Seasonal variations in the physico-chemical parameters of the water of the lake.

\begin{tabular}{lccccccc}
\hline Water parameters & \multicolumn{2}{c}{ Monsoon } & \multicolumn{2}{c}{ Winter } & \multicolumn{2}{c}{ Summer } & Standard of \\
\cline { 2 - 6 } & Ave. \pm SE & Range & Ave. \pm SE & Range & Ave. \pm SE & Range & DoE (2003) \\
\hline Air temperature $\left({ }^{\circ} \mathrm{C}\right)$ & $29.72 \pm 1.92$ & $31.3-27$ & $22.07 \pm 2.41$ & $25.1-23.3$ & $28.62 \pm 3.38$ & $31.1-23.3$ & - \\
Water temperature $\left({ }^{\circ} \mathrm{C}\right)$ & $30.05 \pm 2.07$ & $31.6-27$ & $21.95 \pm 2.37$ & $24.8-190$ & $28.52 \pm 3.22$ & $30.2-23.1$ & 40 \\
DO $(\mathrm{mg} / \mathrm{l})$ & $5.9 \pm 0.29$ & $6.9-4.3$ & $6 . .7 \pm 0.28$ & $7.2-5.58$ & $6.6 \pm 0.71$ & $7.8-4.4$ & $4.5-8$ \\
pH & $6.9 \pm 0.67$ & $7.6-6.2$ & $7.2 \pm 0.35$ & $7.6-6.3$ & $7.4 \pm 3.36$ & $8.1-7.1$ & $6-9$ \\
Depth $(\mathrm{cm})$ & $120.5 \pm 16.5$ & $120-112$ & $84 \pm 5.3$ & $90-78$ & $100 \pm 16.8$ & $120-75$ & - \\
\hline
\end{tabular}

During present investigation the water parameters were within acceptable ranges of inland water fisheries standard (DoE 2003). Soil pH, soil organic carbon and soil organic matter ranged 6.2-6.7, 1.4$2.08 \%$ and $2.5-3.59 \%$, respectively. The results of our experiments showed maximum value in summer and minimum in monsoon (Fig. 7). Fig. 8 bears a relation of benthos population with soil organic carbon and soil organic matter which stands as a good configurative structure.

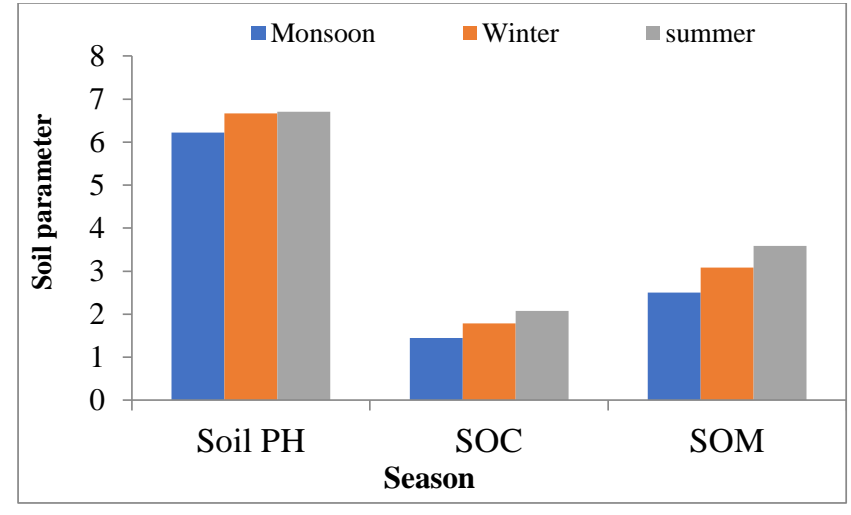

Fig. 7. Seasonal variation of physico-chemical parameters of soil.

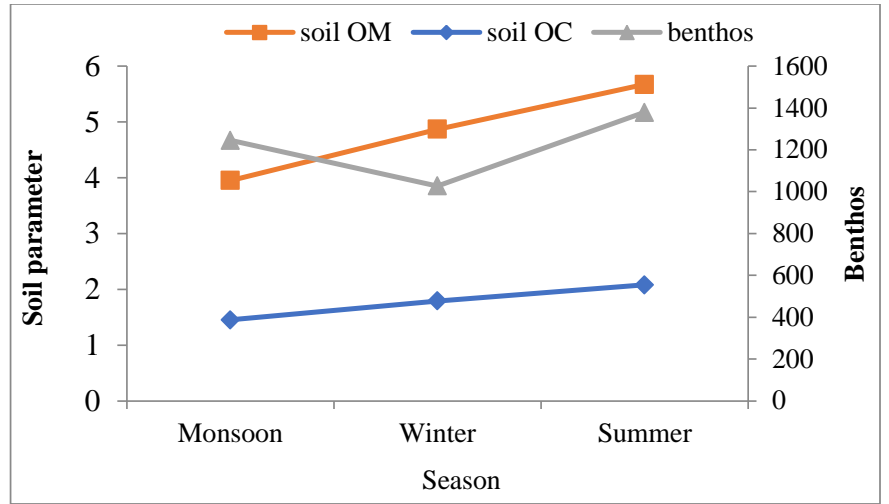

Fig. 8. Benthic abundance in relation with soil organic carbon and soil organic matter.

The correlation between benthic group and environmental parameters was highly divergent. The case of Phylum Mollusca and Annelida showed strong positive correlation with water temperature, water $\mathrm{P}^{\mathrm{H}}$, water depth, soil organic carbon and soil organic matter whereas phylum Arthropoda showed negative relation with soil parameters (Table 4). Previous works done by various authors have shown mixed findings in their experiments. Abhijia and Kumar (2015) reported positive relation of dissolve oxygen and water $\mathrm{pH}$ with benthic fauna and negative with TDS to which present findings showed partial similarity but Ysebaert et al. (2003) reported that the organic matter and sediment characteristics have massive influence in the occurrence of benthic fauna to which present findings showed similarity.

Table 4. Correlation between physicochemical parameters and various benthic fauna.

\begin{tabular}{|c|c|c|c|c|c|c|c|c|c|c|}
\hline Parameter & $\begin{array}{l}\text { Water } \\
\text { temp. }\end{array}$ & $\overline{\text { DO }}$ & $\begin{array}{c}\text { Water } \\
\text { pH }\end{array}$ & Depth & $\begin{array}{c}\text { Soil } \\
\text { pH }\end{array}$ & SOC & SOM & Mollusca & Annelida & Arthropoda \\
\hline Water temp. & 1 & & & & & & & & & \\
\hline DO & -0.77 & 1 & & & & & & & & \\
\hline Water $\mathrm{pH}$ & -0.35 & 0.87 & 1 & & & & & & & \\
\hline Depth & 0.94 & -0.94 & -0.65 & 1 & & & & & & \\
\hline Soil Ph & -0.54 & 0.95 & 0.97 & -0.79 & 1 & & & & & \\
\hline SOC & -0.28 & 0.83 & 0.99 & -0.59 & 0.95 & 1 & & & & \\
\hline SOM & -0.19 & 0.77 & 0.98 & -0.51 & 0.92 & 0.99 & 1 & & & \\
\hline Mollusca & 0.51 & 0.15 & 0.62 & 0.19 & 0.43 & 0.67 & 0.74 & 1 & & \\
\hline Annelida & 0.86 & -0.34 & 0.17 & 0.64 & -0.05 & 0.24 & 0.33 & 0.88 & 1 & \\
\hline Arthropoda & 0.89 & -0.97 & -0.72 & 0.99 & -0.86 & -0.68 & -0.6 & 0.09 & 0.55 & 1 \\
\hline
\end{tabular}

Temp. =Temperature; $\mathrm{SOC}=$ Soil organic carbon; $\mathrm{SOM}=$ Soil organic matter 
It is noteworthy to mention that the macrobenthic diversity of this lake is much diversified and is significantly influenced by some water and soil parameters. Water temperature, water $\mathrm{pH}$, water depth, , Soil organic carbon and soil organic matter strongly influence the abundance and distribution benthic fauna of Mollusca and Annelida. The soil parameters were negatively correlated with Arthropoda and only water temperature and depth influence Arthropod population.

The benthic populations were maximum in summer and minimum in winter; it was probably due to the predation of benthos by winter migratory birds. Dominance of Bellamya spp., Tubifex spp. and Chironomous spp., low diversity indices of Shannon-Wiener' ( $H^{\prime}$ ) index and medium taxa richness clearly demonstrated that this lake is moderately polluted and this lake is not suitable for fish culture especially during winter. It is to be mentioned that more attention should be given in the field of interacting and interrelationship between aquatic vegetation and soil textural type of the lake. Therefore, the lake should be treated as a strong monitoring system. Understanding the lake ecosystem and its health status, it is necessary to study on the ecology (life cycle) and macro benthic community.

\section{ACKNOWLEDGEMENTS}

The authors acknowledge the financial assistance received from "Prime Ministers Higher Education fund" of GoB. The authors are also thankful to the authority of Jahangirnagar University to allow for working on the migratory bird visiting lake.

\section{REFERENCES}

Abhijia, U. G. and A. B. Kumar. 2015.Biomonitoring for pollution assessment; A case study in Veli- akkulum and Vellayani lakes, south west coast of Kerala. J. Aqu. Biol.Fish. 3: 80-89.

Ali, S. and E. Chakrabarti. 1992. A Book of Freshwater Invertebrate of Bangladesh, Bangla Academy, Dhaka. $252 \mathrm{pp}$.

Barnes, R. D. and S. Hughes. 1988. An introduction to marine ecology. 2nd ed. Blackwell Scientific Publications, UK. $351 \mathrm{pp}$.

Bilgrami, K. S. and J. S. D. Munshi. 1985. Ecology of river Ganges: Impact on human activities and conservation of aquatic biodata (Patna to Farakka), Allied Press, Bhagalpur, India., pp. 1-97.

Chakma, S., M. M. Rahman and M. Akter. 2015. Composition and Abundance of Benthic Macro-invertebrates in Freshwater Earthen Ponds of Noakhali District, Bangladesh, American J. Bio. Bioeng. 3(5): 50-56.

DoE. 2003. A Compilation of Environmental Laws of Bangladesh. Department of Environment., pp. 212-214.

Edmonson, W. T. 1959. Fresh water Biology. 2nd ed. John Wiley and Sons Inc, New York. 1248 pp.

George, A. D. I., J. F. N. Abowei and E. R. Daka. 2009. Benthic Macro Invertebrate Fauna and Physico-chemical Parameters in Okpoka Creek Sediments, Niger Delta, Nigeria, Int. J. Ani. Veterinary Adv. 1(2): 59-65.

Ghosh, D. and J. K. Biswas. 2015. Macro invertebrate diversity indices: A Quantitative Bio-assessment of Ecological Health status of an Oxbow Lake in Eastern India. J. Adv. Environ. Health Res. 3(2): 78-90.

Hossain, M. B. 2009. Macro-zoo-benthos of the Meghna River estuarine bed with special reference to Polychaete faunal biodiversity. Int. J. Sustain. Ag. Tech. 5(3): 11-16.

Idowu, E. O. and A. A. A. Ugwumba. 2005. Physical, chemical and benthic faunal characteristics of a Southern Nigeria Reservoir. The Zoologist. 3: 15-25.

Islam, M. N. 2001. An Introduction to statistics and probability. Book world publ. Company, Dhaka, 265 pp.

Jackson, M. L. 1973. Soil Chemical Analysis. Publ. Constable and Co. Ltd, London, U.K. 
Khan, A. N., D. Kamal, M. M. Mahmud, M. A. Rahman and M. A. Hossain. 2007. Diversity, Distribution and Abundance of Benthos in Mouri River, Khulna, Bangladesh. Int. J. Sus. Crop Prod. 2(5):19-23.

Margalef, R. 1958. Information theory in ecology. Int. J. Gen. Syst. 3: 36-71.

Mellanby, H. 1971. Animal life in Fresh Water. Chapman and Hall, London. 308 pp.

Momtaz. H., A. K. M. R. Alam and S. Hoque. 2010. A Comparative Study of Phytoplankton Diversity in Relation to Water Quality of Migratory Birds Visiting and Non-visiting Wetlands of Savar. Bangladesh J. Environ. Res. 8: 31-38.

Needham, J. G. and P. R. Needham. 1963. A Guide to the study of Freshwater Biology. 5th ed. Liolden-day Inc, San Francisco. 106 pp.

Nupur, N., M. Shahjahan, M. S. Rahman and M. K. Fatema. 2013. Abundance of macrobenthos in relation to bottom soil textural types and water depth in aquaculture ponds. Int. J. Agril. Res. Innov. Tech. 3(2): 1-6.

Penak, R. W. 1778. Fresh water invertebrates of the United States. 2nd ed. John Wiley and Sons, New York. 810 pp.

Pielou, E. C. 1966. Species Diversity and Pattern Diversity in the Study of Ecological Succession. Theor. Boil. 10: 370-383.

Piper, C. S. 1950. Soil and Plant analysis: a Laboratory Manual of Methods for the Extraction of Soils and the Determination of the Inorganic Constituents of Plants. Adelaide Univ Press, Australia. 368 pp.

Plafkin, J., L. Barbour, M. T. K. D. Porter, S. K. Gross and R. M. Hughes. 1989. Rapid Bio assessment Protocols for use in Streams and Rivers: Benthic Macro invertebrates and Fish. U. S. Environmental Protection Agency.

Rajpar, M. N., M. Zakaria, E. Yousf, and K. A. Kudus. 2010. Species Abundance and Feeding Guilds of Water Birds at Putrajaya Artificial Freshwater Wetland, Selangor peninsular Malaysia. Pak. J. Forestry. 60(2): 1-9.

Rao, N. V. S., A. Dey and S. Barua. 1992. Estuarine and marine mollusks Fauna of West Bengal. Part 9. Zoological Survey of India, Kolkata., pp. 129-268.

Rosenberg, D. M. and V.H. Resh. 1993. Introduction to Freshwater Biomonitoring and Benthic Macroinvertebrates. In: D. M. Rosenberg and V. H. Resh (Eds.). Freshwater Biomonitoring and Benthic Macroinvertebrates. Chapman/Hall, New York., pp. 1-9.

Sarker, J. M., M. S. A. Patwary, A. M. M. B. Uddin, M. M. Hasan, M. H. Tanmay, I. Kanungo and M. R. Parvej. 2016. Macrobenthic Community Structure -An Approach to Assess Coastal Water Pollution in Bangladesh. Fish Aquac. J. 7(1): 157.

Shannon, C. E. and W. Weaver. 1963. The Mathematical Theory of Communication. Urbana University of Illinois Press.

Sultana, S., A. Aziz and M. Feeroz. 2013. Ecology of Wetland Birds. Lap Lambert Academic Publishing. $140 \mathrm{pp}$.

Welch, P. S. 1948. Limnological methods. Mc Graw Hill book Company, New York.

Ysebaert, T., P. M. J. Herman and P. Mierie. 2003. Large scale spatial patterns in estuaries: estuarine macrobenthic communities in the Schelde estuary, NW Europe. Estuarine and coastal shelf science. 57(1-2): 335-355. 